\title{
Effect of loperamide and naloxone on mouth-to-caecum transit time evaluated by lactulose hydrogen breath test
}

\author{
G BASILISCO, A BOZZANI, G CAMBONI, M RECCHIA, M QUATRINI, \\ D CONTE, R PENAGINI, AND P A BIANCHI
}

From the Patologia Medica III, Istituto di Clinica Medica I, University of Milan, and Biostatistics Unit, Istituto di Ricerche Farmacologiche 'Mario Negri', Milan, Italy

SUMMARY The effect of loperamide and naloxone on mouth-to-caecum transit time was evaluated by the lactulose hydrogen breath test in four men and four women. Each subject underwent tests during the administration of placebo, loperamide (12-16 mg po), naloxone (40 $\mu \mathrm{g} / \mathrm{kg} / \mathrm{h}$ by a three-hour intravenous infusion), and loperamide plus naloxone, carried out at intervals of one or two weeks. The transit time was significantly longer after loperamide, and this effect was antagonised by the concomitant administration of naloxone whereas naloxone administered alone had no effect on mean transit time. No clinically important side effects were reported.

Morphine changes the motility pattern in the gastrointestinal tract, ${ }^{1}$ decreases the propulsion of its contents, ${ }^{2}{ }^{3}$ reduces gastric ${ }^{4}$ and intestinal secretions ${ }^{5}$ and increases water and ions absorption. ${ }^{67}$ Loperamide, an opioid agonist, retains most peripheral effects of morphine, many of which are inhibited by the opioid antagonist naloxone,${ }^{8}$ but is nearly devoid of its central nervous system activity.

In patients with irritable bowel syndrome loperamide slows the small bowel transit of a meal ${ }^{9}$ and increases orocaecal transit time as measured by lactulose hydrogen breath test. ${ }^{10}$ The reproducibility of this simple, non-invasive test has recently been questioned $^{11}$ and it has been reported to be influenced by $\operatorname{sex}^{12}$ and menstrual cycle phases; ${ }^{13}$ however, Morley et al $^{14}$ found it adequate to detect the increase of gastrointestinal transit time caused by gluten peptides which are believed to have an opioid-like activity, and the inhibition of this effect by naloxone.

In rats, the opioid antagonists naloxone and $\mathrm{N}$-methylnaloxone have been shown to reverse the morphine-induced increase in gastrointestinal transit time assessed by measuring the length of

Address for correspondence: P A Bianchi, Patologia Medica III, Via Francesco Sforza, 35, 20122 Milano, Italy.

Received for publication 3 August 1984 bowel traversed by a charcoal test meal. ${ }^{15}$ The present study was designed to assess in healthy human subjects of both sexes the effect of loperamide and naloxone on orocaecal transit time measured by the hydrogen breath test.

\section{Methods}

\section{SUBJECTS}

Eight healthy volunteers (four men, age range 25-34 years, mean age 28 years, weight $72,69,68$, and 64 $\mathrm{kg}$; four women, age range $23-26$ years, mean age 25 years, weight $72,50,49$, and $48 \mathrm{~kg}$ ) were studied after having given their informed consent. All volunteers belonged to the medical staff of the clinic and were willing to comply with the conditions needed for the test.

The weekly number of bowel movements was five to 10 in six subjects, three to four in one woman and two to three in another woman. None of the subjects took any medication for at least 72 hours or any antibiotics for at least two months before the beginning of the study, or during it. Subjects were asked to have a standard meal consisting of one serving of boiled rice, a steak, and water ad libitum at $8 \mathrm{pm}$ the day before the test. Then they did not take anything except for the treatments. Smoking was not allowed between midnight and the end of the test. Studies were performed in a quiet 
environment, subjects being at complete rest.

Orocaecal transit time was assessed by means of the hydrogen breath test. ${ }^{16}$ At 930 am the fasting subjects ingested $10 \mathrm{~g}$ lactulose (Duphalac Philips Duphar, Weesp, Holland, $15 \mathrm{ml}$ ) suspended in 100 $\mathrm{ml}$ tap water. End expiratory breath samples were obtained just before and every 10 minutes after the ingestion of lactulose using a modified HaldanePriestley tube. ${ }^{17}$ Samples were immediately analysed for molecular hydrogen using a chromatograph with a thermal conductivity detector (mod. 3200 DANI, Monza, Italy) as described by Zuccato et al. ${ }^{18}$ Values were expressed as $\mathrm{ppm}$ corresponding to $0.045 \mu \mathrm{mol} / \mathrm{l}$. The mean of 12 determinations of standard samples containing 50 ppm $\mathrm{H}_{2}$ were $50.5 \mathrm{ppm} \pm 3.17 \mathrm{SD}$. The $\mathrm{r}$ values of calibration curves obtained from standard samples of $\mathrm{H}_{2}$ (2-100 ppm) were 0.994 .

Orocaecal transit time was defined as the time elapsing between ingestion of lactulose and the first definite and sustained rise of breath hydrogen concentration - that is, an increase of at least $2 \mathrm{ppm}$ above the baseline, maintained or increased in the three following determinations. Hydrogen breath tests were carried out for at least three hours or until the orocaecal transit time was determined. Orocaecal transit time was assessed by a physician not aware of the treatments.

The subjects were divided into two blocks according to sex; each subject was studied on four separate occasions at intervals of one or two weeks. Each time a different treatment (A, B, C or D) was given, the sequence being as follows: subject 1 , CADB; subject 2, $A B C D$; subject 3 , BDAC; subject 4 , DCBA; subject $5, \mathrm{BCDA}$; subject 6 , DCBA; subject 7, BDAC; subject 8, CABD. The treatments were known only to the physician in charge of administering them. The treatments were administered as follows: at $10 \mathrm{pm}$ the day before and at $830 \mathrm{am}$ on the day of the test the five subjects weighing over $50 \mathrm{~kg}$ were given four capsules and the remaining three subjects three capsules with a sip of tap water. On the day of the test from 9-9 30 am each subject was given an intravenous infusion of saline $100 \mathrm{ml}$, and from $930 \mathrm{am}-1230 \mathrm{pm}$, while the hydrogen breath test was carried out, a further intravenous infusion of saline $500 \mathrm{ml}$ with or without the study drug. If the hydrogen breath test was not stopped at 1230 a further intravenous infusion of saline (with or without the study drug) was given until the end of the test.

Treatment A consisted of placebo infusion and placebo capsules, treatment $\mathrm{B}$ of placebo infusion and loperamide capsules, treatment $\mathrm{C}$ of naloxone infusion and placebo capsules, and treatment $D$ of naloxone infusion and loperamide capsules.
Loperamide (Lopemid Gentili, Pisa, Italy) was given as capsules of $2 \mathrm{mg}$ each and naloxone hydrochloride (Narcan Crinos, Villa Guardia, Italy) was given at doses of $40 \mu \mathrm{g} / \mathrm{kg} / \mathrm{h}$.

Symptoms and bowel movements during the 48 hours after the start of the test were recorded as well as the day of the menstrual cycle. The female subjects were not on oral contraceptives; four of the 16 tests on these subjects were undertaken during the luteal phase of the menstrual cycle.

Statistical analysis was performed with split-plot design (between-within subjects ANOVA) followed by Tukey's test for multiple comparisons ${ }^{19}$ and Fisher's exact test for frequency data.

\section{Results}

The orocaecal transit time in each subject according to treatments and the results of the analysis of variance are reported in the Table.

The difference in transit time between sexes was not statistically significant. In men and women loperamide prolonged transit time in comparison with the other treatments (Tukey's test: $p<0.05$ ) while transit times during naloxone and loperamide plus naloxone administration were not statistically different from placebo or from each other. Only in subject 7, who had two to three bowel movements per week, transit time was not affected by loperamide and was reduced by naloxone.

During the 48 hours after the start of the test there

Table Orocaecal transit time in minutes according to treatments in 4 males and 4 females

\begin{tabular}{|c|c|c|c|c|}
\hline & \multicolumn{4}{|c|}{ Treatments } \\
\hline & $\begin{array}{c}A \\
\text { Placebo }\end{array}$ & $\begin{array}{c}B \\
\text { Loperamide }\end{array}$ & $\begin{array}{c}C \\
\text { Naloxone }\end{array}$ & $\begin{array}{c}D \\
\text { Loperamide } \\
+ \text { naloxone }\end{array}$ \\
\hline \multicolumn{5}{|l|}{ Men } \\
\hline 1 & 90 & 180 & 90 & 90 \\
\hline 2 & 60 & 110 & 60 & 80 \\
\hline 3 & 60 & 200 & 70 & 50 \\
\hline 4 & 50 & 140 & 50 & 40 \\
\hline mean & $65 \cdot 0$ & $157 \cdot 5$ & $67 \cdot 5$ & $65 \cdot 0$ \\
\hline SD & $17 \cdot 3$ & $40 \cdot 3$ & $17 \cdot 1$ & $23 \cdot 8$ \\
\hline \multicolumn{5}{|l|}{ Women } \\
\hline 5 & 50 & 90 & $30^{*}$ & 50 \\
\hline 6 & $80^{*}$ & 170 & 80 & 60 \\
\hline 7 & $140^{*}$ & $140^{*}$ & 100 & 150 \\
\hline 8 & 120 & 220 & 130 & 120 \\
\hline mean & $97 \cdot 5$ & $155 \cdot 0$ & $85 \cdot 0$ & $95 \cdot 0$ \\
\hline SD & $40 \cdot 3$ & $54 \cdot 5$ & $42 \cdot 0$ & $47 \cdot 9$ \\
\hline
\end{tabular}

* Female subjects in luteal phase of menstrual cycle.

Analysis of variance: between sexes NS.

between treatments $\mathrm{p}<0.000004$. sexes $\times$ treatments NS. 
was a higher frequency of subjects with no bowel movements after administration of loperamide with (five subjects) or without (six subjects) naloxone compared with placebo (two subjects) or naloxone (one subject). Borborygmi, pain and abdominal distension were present in nearly the same frequency in all treatments. Headache was more frequent in subjects treated with naloxone alone (four subjects) or with loperamide (three subjects) compared with placebo (no subjects) or loperamide (two subjects) with a statistically significant difference $(p=0.03)$ between treatments $A$ and $C$. Borborygmi, pain, abdominal distension and headache always disappeared within eight hours after the start of the test and were mild and easily tolerated.

\section{Discussion}

Gastrointestinal transit time in rats, assessed by charcoal test meal, is prolonged by morphine and this effect is antagonised by naloxone or by its peripherally selective $\mathrm{N}$-methyl analogue. ${ }^{2} 15$ These data are consistent with our findings in man, showing the increase in transit time induced by the peripheral opioid agonist loperamide was antagonised by naloxone.

In seven of our eight subjects the administration of naloxone did not seem to affect the orocaecal transit time, as previously suggested by similar results in rats. ${ }^{20}$ Rees et al reported a modification by naloxone of the antroduodenal motility pattern in man, ${ }^{21}$ but Feldman et al showed that the gastric emptying of a liquid meal is not influenced by this drug. ${ }^{4}$ Moreover, gastric emptying of liquids does not seem to affect human orocaecal transit time assessed by lactulose hydrogen breath test. ${ }^{22}$

In our study the inhibition of the effect of loperamide by naloxone was obtained by administering the antagonist by the intravenous route to avoid the first passage through the liver; other authors ${ }^{14}$ reported that naloxone administered po had an effect on mouth-to-caecum transit time delayed by hydrolysed gluten, suggesting a possible purely local effect on the gut.

Lawson et al reported that the orocaecal transit time in women was significantly longer than in men. ${ }^{12}$ This result was not confirmed by our study probably because of the large inter-individual variability and the small number of subjects studied.

A possible bias which might increase the intraindividual variability of the test in women is the luteal phase of the menstrual cycle which is reported to prolong transit time. ${ }^{13} \mathrm{We}$ carried out four of the 16 tests in women in the luteal phase of the menstrual cycle in order to limit the time between the four tests in each subject, and the variations were not so great as to prevent obtaining a statistically significant result in the group of women.

Our results were obtained using the lactulose hydrogen breath test, a simple and well tolerated investigation technique: the side effects reported were mild, quickly self-limiting and easily tolerated by the volunteers.

Recently La Brooy et al denied the reproducibility of the lactulose hydrogen breath test in and between individuals. ${ }^{11}$ We did not study the reproducibility of the test and no data are available to compare with La Brooy et al's results. In our experimental conditions, however, and using each subject as his-her own control, in accordance with Corbett $e t$ al's previous findings, ${ }^{10}$ the reproducibility in individuals of this technique was adequate to detect the effect of loperamide on mouth-to-caecum transit time.

The authors thank Alix Green for help in the preparation of the manuscript and Tiziana Arienti for secretarial assistance.

\section{References}

1 Mackerer CR, Clay GA, Dajani EZ. Loperamide binding to opiate receptors sites of brain and myenteric plexus. J Pharmacol Exp Ther 1976; 199: 131-40.

2 Wong C-L, Roberts MB, Wai M-K. Effect of morphine and naloxone on intestinal transit in mice. Eur $J$ Pharmacol 1980; 64: 289-95.

3 Fiocchi R, Bianchi G, Petrillo P, Tavani A, Manara L. Morphine inhibits gastrointestinal transit in the rat primarily by impairing propulsive activity of the small intestine. Life Sci 1982; 31: 2221-3.

4 Feldman M, Walsh JH, Taylor IL. Effect of naloxone and morphine on gastric acid secretion and on serum gastrin and pancreatic polypeptide concentrations in humans. Gastroenterology 1980; 79: 294-8.

5 McKay JS, Linaker BD, Higgs NB, Turnberg LA. Studies of the anti-secretory activity of morphine in rabbit ileum in vitro. Gastroenterology 1982; 82: 243-7.

6 McKay JS, Linaker BD, Turnberg LA. Influence of opiates on ion transport across rabbit ileal mucosa. Gastroenterology 1981; 80: 279-84.

7 Warhurst G, Smith G, Tonge A, Turnberg LA. Effects of morphine on net water absorption, mucosal adenylate cyclase activity and $\mathrm{PGE}_{2}$ metabolism in rat intestine. Eur J Pharmacol 1983; 86: 77-82.

8 Awouters F, Niemegeers CJE, Janssen PAJ. Pharmacology of antidiarrheal drugs. Ann Rev Pharmacol Toxicol 1983; 23: 279-301.

9 Cann PA, Read NW, Holdsworth CD, Barends D. Role of loperamide and placebo in management of irritable bowel syndrome (IBS). Dig Dis Sci 1984; 29: 239-47. 
10 Corbett CL, Thomas S, Read NW, Hobson N, Bergman I, Holdsworth CD. Electrochemical detector for breath hydrogen determination: measurement of small bowel transit time in normal subjects and patients with the irritable bowel syndrome. Gut 1981; 22: 836-40.

11 La Brooy SJ, Male P-J, Beavis AK, Misiewicz JJ. Assessment of the reproducibility of the lactulose $\mathrm{H}_{2}$ breath test as a measure of mouth to caecum transit time. Gut 1983; 24: 893-6.

12 Lawson M, Everson GT, Klingensmith W, Kern F Jr. Coordination of gastric and gallbladder emptying after ingestion of a regular meal. Gastroenterology 1983; 85: 866-70.

13 Wald A, Van Thiel DH, Hoechstetter AL, et al. Gastrointestinal transit: the effect of the menstrual cycle. Gastroenterology 1981; 80: 1497-500.

14 Morley JE, Levine AS, Yamada T, et al. Effect of exorphins on gastrointestinal function, hormonal release, and appetite. Gastroenterology 1983; 84: 151723.

15 Bianchi G, Ferretti P, Recchia M, Rocchetti M, Tavani A, Manara L. Morphine tissue levels and reduction of gastrointestinal transit in rats. Correlation supports primary action site in the gut. Gastroenterology 1983; 85: $852-8$.
16 Bond JH Jr, Levitt MD. Investigation of small bowel transit time in man utilizing pulmonary hydrogen $\left(\mathrm{H}_{2}\right)$ measurements. J Lab Clin Med 1975; 85: 546-55.

17 Metz G, Gassul MA, Leeds AR, Blendis LM, Jenkins DJA. A simple method of measuring breath hydrogen in carbohydrate malabsorption by end-expiratory sampling. Clin Sci Mol Med 1976; 50: 237-40.

18 Zuccato $\mathrm{E}$, Andreoletti $\mathrm{M}$, Bozzani A, et al. Respiratory excretion of hydrogen and methane in Italian subjects after ingestion of lactose and milk. Eur J Clin Invest 1983; 13: 261-6.

19 Kirk RE. Split-plot design. Factorial design with block-treatment confounding. In: Experimental design: procedures for the behavioural sciences. Belmont, California: Brooks/Cole Publishing Company, 1968. 245-318.

20 Tavani A, Bianchi G, Ferretti P, Manara L. Morphine is most effective on gastrointestinal propulsion in rats by intra-peritoneal route: evidence for local action. Life Sci 1980; 27: 2211-7.

21 Rees WDW, Sharpe GR, Christofides ND, Bloom SR, Turnberg LA. The effects of an opiate agonist and antagonist on the human upper gastrointestinal tract. Eur J Clin Invest 1983; 13: 221-5.

22 Cobden I, Barker MCJ, Axon ATR. Gastrointestinal transit of liquids. Ann Clin Res 1983; 15: 119-22. 